\title{
Y-Stent-Assisted Coiling With Low-Profile Neuroform Atlas Stents for Endovascular Treatment of Wide-Necked Complex Intracranial Bifurcation Aneurysms
}

\section{Kubilay Aydin, MD** \\ Sinan Balci, MD ${ }^{\S}$ \\ Serra Sencer, MD* \\ Mehmet Barburoglu, MD* \\ Muzaffer Reha Umutlu, MD* \\ Anil Arat, MD}

* Neuroradiology Division, Department of Radiology, Istanbul Faculty of Medicine, Istanbul University, Istanbul, Turkey; ${ }^{\ddagger}$ Department of Interventional Radiology, Koc University Hospital, Istanbul, Turkey; ${ }^{\S}$ Department of Radiology, Hacettepe University Hospital, Ankara, Turkey

\section{Correspondence: \\ Kubilay Aydin, MD, \\ Neuroradiology Division, \\ Department of Radiology, \\ Istanbul Faculty of Medicine, \\ Istanbul University, \\ Topkapı, Turgut Özal Millet Cd, \\ 34093 Istanbul, Turkey. \\ Email:dr.aydink@gmail.com}

Received, July 3, 2019.

Accepted, September 20, 2019.

Copyright (C) 2019 by the

Congress of Neurological Surgeons

BACKGROUND: Y-stent-assisted coiling is one of the eligible techniques for the treatment of complex bifurcation aneurysms. In majority of previous literature, Y-stenting has been performed using stents that could be delivered through large profile microcatheters that are often difficult to manipulate during navigation through sharply angled side branches. Attempts to navigate with these large profile catheters might cause serious complications during Y-stenting procedure.

OBJECTIVE: To investigate the safety, feasibility, and efficacy of Y-stent-assisted coiling procedure with Neuroform Atlas stents for the treatment of complex bifurcation aneurysms; Neuroform Atlas is a recently introduced open-cell stent that can be delivered though low-profile microcatheters.

METHODS: We identified the patients with intracranial bifurcation aneurysms treated by Y-stent-assisted coiling procedure with Neuroform Atlas stents. We assessed the immediate postoperative and follow-up clinical and angiographic outcomes. We also investigated the periprocedural and delayed complications.

RESULTS: A total of 30 aneurysms in 30 patients were included in the study. Y-stenting was successfully performed without any technical complications in all cases (100\%). Immediate postprocedural angiography revealed total aneurysm occlusion in $83.3 \%$ of patients. The mean angiographic follow-up time was 11.8 mo. The last follow-ups showed complete occlusion in $93.3 \%$ of patients. There was no mortality in this study. A procedure-related complication developed in $6.7 \%$ and resulted in permanent morbidity in $3.3 \%$ of patients. CONCLUSION: Neuroform Atlas stent combines the advantages of low-profile deployment microcatheters with an open-cell structure to achieve a successful Y-stenting procedure. Y-stent-assisted coiling with Neuroform Atlas stents provides a safe and effective endovascular treatment for wide-necked complex bifurcation aneurysms.

KEY WORDS: Aneurysm, Bifurcation, Endovascular, Stenting, Coiling, Neuroform Atlas stent, Y-stenting

Neurosurgery 0:1-10, 2019

DOI:10.1093/neuros/nyz516

www.neurosurgery-online.com

n 2002, the first dedicated stent was introduced to assist in the coiling of widenecked aneurysms. ${ }^{1}$ Deployment of a stent across the wide neck of an aneurysm creates a mechanical scaffold to prevent the protrusion of coils. Furthermore, the hemodynamic and

ABBREVIATIONS: Acom, anterior communicating artery; DSA, digital subtraction angiography; MR, magnetic resonance; $\mathbf{M C A}$, middle cerebral artery; mRS, modified Rankin scale; RR, Raymond-Roy; WEB, Woven EndoBridge biological effects of stents promote progressive thrombosis of aneurysms and impede recanalization. ${ }^{2,3}$ Despite the significant contributions of stents, endovascular treatment of complex bifurcation aneurysms possessing a neck that incorporates more than one side branch remains a challenge for surgeons. Endovascular treatment of these complex bifurcation aneurysms does not infrequently necessitate the implantation of 2 stents (dual stenting) in various configurations. ${ }^{4-8}$

Y-stent-assisted coiling was first described by Chow et al. ${ }^{4}$ Y-stenting has been performed 
using various combinations of open- and/or closed-cell stents, as reported in early studies reporting the results of the Y-stentassisted coiling procedure. The stents used in these early Y-stenting studies could be delivered through microcatheters with an internal diameter of 0.027 or 0.021 in. ${ }^{4,6,9,10}$ These catheters, which have relatively large profiles, are often difficult to manipulate so that they navigate through the sharply angled and small-sized side branches of bifurcations. Furthermore, during Y-stenting, attempts to perform catheterization with these relatively large profile catheters through the struts of the initially deployed stent might result in the deformation and dislocation of the stent. ${ }^{6,11}$ Recently, low-profile stents have been introduced for the treatment of wide-necked aneurysms. These low-profile intracranial stents can be delivered through microcatheters with an internal diameter of 0.0165 in, and this allows them to be more easily navigated through small-sized, delicate vessels and, thereby, improves the safety of stenting during treatment for distal wide-necked aneurysms. ${ }^{7}, 12,13$ The Neuroform Atlas stent (Stryker, Los Angeles, California) is a recently developed lowprofile self-expandable stent with an open-cell design. ${ }^{13}$ Recent case series assessing the outcomes of stent-assisted coiling procedures performed using Neuroform Atlas stents have provided promising results. ${ }^{13-15}$ Deliverability through low-profile microcatheters and open-cell design are the technical features of Neuroform Atlas stent that may allow to perform a safe Y-stenting procedure. The number of the cases treated with Y-stent-assisted coiling procedure using Neuroform Atlas stents is very limited in the literature. ${ }^{14-17}$ In this retrospective study, we aimed to investigate the safety, efficacy and midterm durability of the Y-stentassisted coiling operation when performed using 2 Neuroform Atlas stents for the treatment of wide-necked intracranial bifurcation aneurysms.

\section{METHODS}

After approval of the institutional review board was obtained, the database records of 3 centers were reviewed. Patients' consent was not sought for this retrospective study. Patients with an intracranial bifurcation aneurysm treated with the assistance of 2 Neuroform Atlas stents in the Y-stenting configuration were identified. The decision regarding the most appropriate method of treatment in every case was made by our multidisciplinary neurovascular teams considering the multiple factors including the morphology of aneurysm. We performed Y-stent-assisted coiling operation to treat the broad-necked bifurcation aneurysms having complex neck morphology. Wide-necked aneurysms were defined as aneurysms with a dome-to-neck ratio of $<2$ or a neck diameter of $>4$ $\mathrm{mm}$. Complex bifurcation aneurysms were defined as wide-necked bifurcation aneurysms that incorporated more than one side branch of the bifurcation. The patients' demographic data in addition to the location and size of aneurysms, procedural details, and technical and clinical complications were recorded.

\section{Endovascular Procedure}

All elective patients received dual antiplatelet therapy consisting of $75 \mathrm{mg}$ of clopidogrel (Plavix, Bristol-Myers Squibb) and $300 \mathrm{mg}$ of aspirin (Coraspin, Bayer) daily. The level of antiaggregation activity provided by clopidogrel was tested with impedance-aggregometry $(<45$ activity unit; Multiplate Analyzer, Roche). During the procedure, the more-difficult-to-approach side branch of the bifurcation was catheterized first using an Excelsior SL-10 (Stryker) for stenting. Then, another microcatheter with an internal diameter of 0.0165 in (Excelsior SL-10 or Headway 17; MicroVention/Terumo, Tustin, California) was jailed in the aneurysm sac for coiling. The first Neuroform Atlas stent was then deployed into the difficult branch of the bifurcation. Then, the second branch of the bifurcation was catheterized by passing the same Excelsior catheter through the struts of the initially deployed stent. A second Neuroform Atlas stent was deployed into the second side branch, creating a Y configuration when combined with the first deployed stent. After the deployment of the stents, coiling was performed using bare platinum coils. The aneurysms were coiled until completely occluded or until no further coils could be safely deployed. Postprocedural dual antiplatelet treatment was continued for 3 mo. Antiplatelet therapy was switched to $100 \mathrm{mg}$ of aspirin thereafter.

\section{Follow-ups}

Immediate postprocedural control digital subtraction angiography (DSA) images were obtained to evaluate aneurysm occlusion according to the Raymond-Roy ${ }^{18}$ (RR) classification and the patency of the target vessels. The first angiographic follow-up was performed at 3 to 6 mo using either magnetic resonance (MR) angiography or DSA. The second angiographic follow-up using DSA was performed 9 to 15 mo after the endovascular procedure. After the second angiographic follow-up, the patients were annually followed with MR angiography. Progressive thrombosis of the aneurysm sac on follow-up imaging was defined as an improvement in RR class from sac or neck filling (RR class 3 or 2) toward total occlusion (RR class 1). Recanalization was defined as deterioration in the RR class. The angiographic images were evaluated by 2 experienced surgeons (K.A. and A.A.) who were blinded to the clinical outcomes.

Patients' neurological statuses were evaluated preoperatively at discharge and during angiographic follow-ups using the modified Rankin scale (mRS). Any clinical symptoms or signs that developed during the postoperative period were recorded. Complications that developed during the endovascular procedure or within $30 \mathrm{~d}$ following the operation were defined as periprocedural. Clinical complications that developed more than $30 \mathrm{~d}$ later were considered delayed complications. Morbidity was defined as an $\mathrm{mRS}$ score $>2$.

\section{Statistical Analysis}

The descriptive statistical analysis was performed by using SPSS statistics (IBM, Armonk, New York).

\section{RESULTS}

\section{Patients and Aneurysm Characteristics}

A total of 30 patients (20 females) with 30 aneurysms were identified (Table 1). The mean age of the included patients was $52.4 \pm 8.9 \mathrm{yr}$ old (range, 34-66 yr old). Three patients presented with subarachnoid hemorrhage, and the remaining 27 patients $(90 \%)$ had unruptured aneurysms. No patient was stented during the acute phase of subarachnoid hemorrhage $(<10 \mathrm{~d})$. The mean dome size of the aneurysms was $6.9 \pm 2.2 \mathrm{~mm}$ (range, $4-16 \mathrm{~mm}$ ) (Figure 1). The mean diameter of bifurcation side branches 


\begin{tabular}{|c|c|}
\hline \multicolumn{2}{|l|}{ Demographics } \\
\hline Mean age & $52.4 \pm 8.9 \mathrm{yr}$ \\
\hline \multicolumn{2}{|l|}{ Sex } \\
\hline Female & $20(66.7 \%)$ \\
\hline Male & $10(33.3 \%)$ \\
\hline \multicolumn{2}{|l|}{ Clinical presentation } \\
\hline Incidental & $20(66.7 \%)$ \\
\hline Headache & $5(16.6 \%)$ \\
\hline $\mathrm{SAH}$ & $3(10 \%)$ \\
\hline Recurrence & $2(6.7 \%)$ \\
\hline \multicolumn{2}{|l|}{ Aneurysm location } \\
\hline MCA & $17(56.7 \%)$ \\
\hline Acom & $10(33.3 \%)$ \\
\hline Basilar tip & $2(6.7 \%)$ \\
\hline Pericallosal artery & $1(3.3 \%)$ \\
\hline \multicolumn{2}{|l|}{ Aneurysm size } \\
\hline$<7 \mathrm{~mm}$ & $16(53.3 \%)$ \\
\hline $7-10 \mathrm{~mm}$ & $12(40 \%)$ \\
\hline $10-15 \mathrm{~mm}$ & $1(3.3 \%)$ \\
\hline $15-20 \mathrm{~mm}$ & $1(3.3 \%)$ \\
\hline
\end{tabular}

Acom $=$ anterior communicating artery, $\mathrm{MCA}=$ middle cerebral artery, and $\mathrm{SAH}=$ subarachnoid hemorrhage.

was $2.2 \pm 0.3 \mathrm{~mm}$ (range, 1.6-2.9 $\mathrm{mm}$ ). Two aneurysms were recanalized aneurysms that were treated previously using balloonassisted coiling and the implantation of an intrasaccular flow disruptor (Figure 2). Y-stenting was performed intentionally in all but 1 patient. In the treatment of 1 patient with a ruptured wide-necked anterior communicating artery (Acom) aneurysm, Y-stent-assisted coiling was performed as a bailout technique after coil protrusion developed during the double balloon-assisted coiling procedure (Figure 3). During the procedure of this patient, the stents were deployed following a bolus dose of $0.25 \mathrm{mg} / \mathrm{kg}$ tirofiban (Aggrastat; Merck). At the end of the procedure, loading doses of $450 \mathrm{mg}$ of clopidogrel were given via nasogastric tube, and tirofiban was infused at a rate of $0.15 \mathrm{mcg} / \mathrm{kg} / \mathrm{min}$ continuously for $6 \mathrm{~h}$ until the clopidogrel achieved sufficient antiaggregant activity.

The preoperative mRS scores of all patients except 1 were 0 . One patient was assigned a preprocedural $\mathrm{mRS}$ score of 2 because of recent subarachnoid hemorrhage.

\section{Immediate Angiographic Results}

The deployment of 2 Neuroform Atlas stents was successfully performed in all cases. In 4 cases, the coiling microcatheter was kicked back out of the aneurysm sac during coiling procedure, and the sacs were uneventfully recatheterized by passing the catheter through the stent struts. No technical complications developed during the stent deployment or coiling procedures. The immediate control DSA images revealed that total aneurysm occlusion (RR1) was achieved in 25 patients (83.3\%), neck filling (RR2) in 4 aneurysms (13.3\%), and sac filling (RR3) in 1 aneurysm $(3.3 \%)$.

\section{Complications}

There was no mortality in this study. Compared to the results of preoperative neurological examinations, the immediate postprocedural neurological examinations did not reveal new symptoms or findings. A periprocedural $(3.3 \%)$ or delayed complication (3.3\%) developed in 2 patients $(6.7 \%)$. These complications resulted in permanent morbidity in 1 patient $(3.3 \%)$.

Six-month follow-up MR imaging of a patient with a right middle cerebral artery (MCA) bifurcation aneurysm revealed a clinically silent cortical infarction in the right temporal lobe (Figure 4). His neurological examinations at the clinical followups did not reveal any pathological findings. His mRS score at the last follow-ups remained zero. Twelve-month follow-up DSA revealed the total occlusion of the aneurysms and the patency of all bifurcation vessels. Another patient with an MCA aneurysm developed contralateral hemiplegia after antiplatelet therapy was stopped as a result of the patient's decision $3 \mathrm{wk}$ after the endovascular procedure. Cranial MR imaging examination revealed the infraction of the whole territory of the MCA superior trunk. Her DSA examination showed the occlusion of the superior trunk of the MCA and RR class 1 occlusion of the aneurysm. The mRS score of this patient was 4 at the last clinical follow-up.

\section{Follow-ups}

The mean length of angiographic follow-up was $11.8 \pm 7.8 \mathrm{mo}$ (range, 6-36 mo). Six-month follow-up of 1 patient with an initial $\mathrm{RR}$ with class $3 \mathrm{sac}$ filling on the immediate postprocedural DSA revealed persistent filling of the aneurysm sac. This patient was retreated by coiling of the persistently filling sac. His 12-mo follow-up DSA showed complete occlusion of the aneurysm (RR class 1 ). The final follow-up angiograms of all patients revealed that RR class 1 occlusion was achieved in 28 patients $(93.3 \%)$ and that RR class 2 occlusions were achieved in 2 patients $(6.7 \%)$ (Table 2 and Figure 5). The follow-ups of 2 aneurysms (6.7\%) with partial immediate occlusion (RR class 2 ) revealed complete occlusion (RR class 1) (progressive occlusion). We did not observe recanalization in any patient.

The last clinical follow-ups of 28 of 30 patients revealed an mRS score of zero. The final mRS score of the patient who developed a delayed ischemic complication was 4 . We did not observe any change in the follow-up mRS score of the patient with a preoperative $\mathrm{mRS}$ score of 2 .

\section{DISCUSSION}

Some new endovascular devices, such as an intrasaccular flow disruptor and neck-reconstruction implants, have been recently developed for the treatment of wide-necked bifurcation aneurysms. The Woven EndoBridge (WEB) device is an intra-aneurysmal flow disruptor that was designed for the 

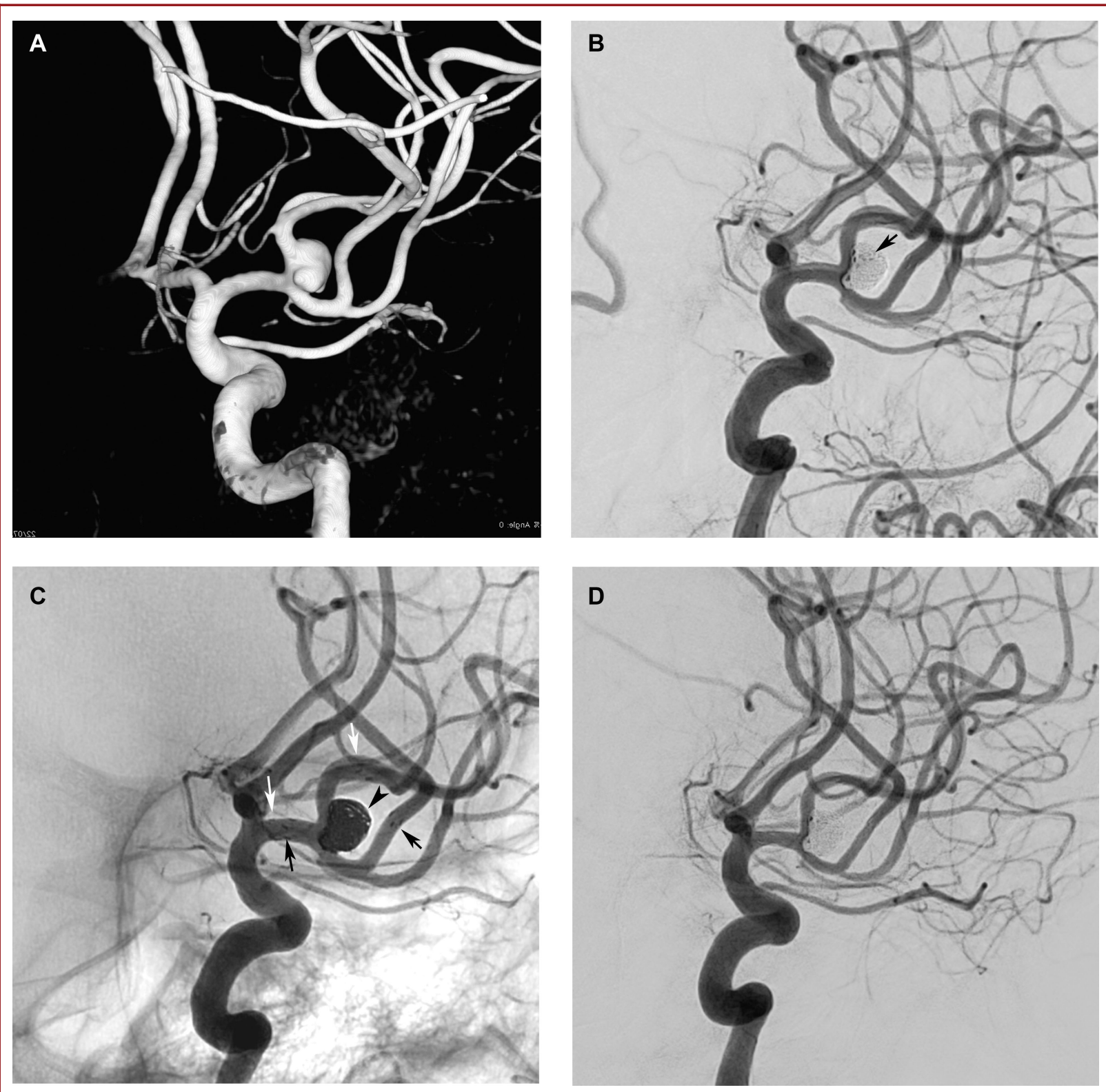

FIGURE 1. Procedural and follow-up angiography images of a 47-yr-old female patient with an unruptured left MCA aneurysm. A, Preprocedural 3-dimensional reconstructed angiography image showing a wide-necked MCA aneurysm with a complex morphology. B. Immediate postprocedural DSA image revealing the complete occlusion of the sac (arrow) and patency of all vessels. C, Immediate postprocedural nonsubstracted angiography image shows 2 Neuroform Atlas stent (black and white arrows) deployed into the superior and inferior trunks of the MCA and coils inside the aneurysm sac (arrowhead). D, Six-month follow-up DSA image demonstrating the complete occlusion of the aneurysm.

treatment of wide-necked bifurcation aneurysms. ${ }^{19,20}$ However, the morphology of some aneurysms may not be appropriate for successful treatment with WEB implantation. Previous studies showed that the after WEB implantation, aneurysm occlusion rates were dependent on the size and morphology of the aneurysm. ${ }^{19,20}$ Other devices, such as PulseRider, have been developed to reconstruct a bifurcation to provide support at the aneurysm neck while protecting the branches of the bifurcation during the coiling. Two recent studies demonstrated the safety and feasibility of the PulseRider-assisted coiling procedure for basilar and carotid bifurcation aneurysms. ${ }^{21,22}$ However, the number of patients with Acom or MCA aneurysms reported 

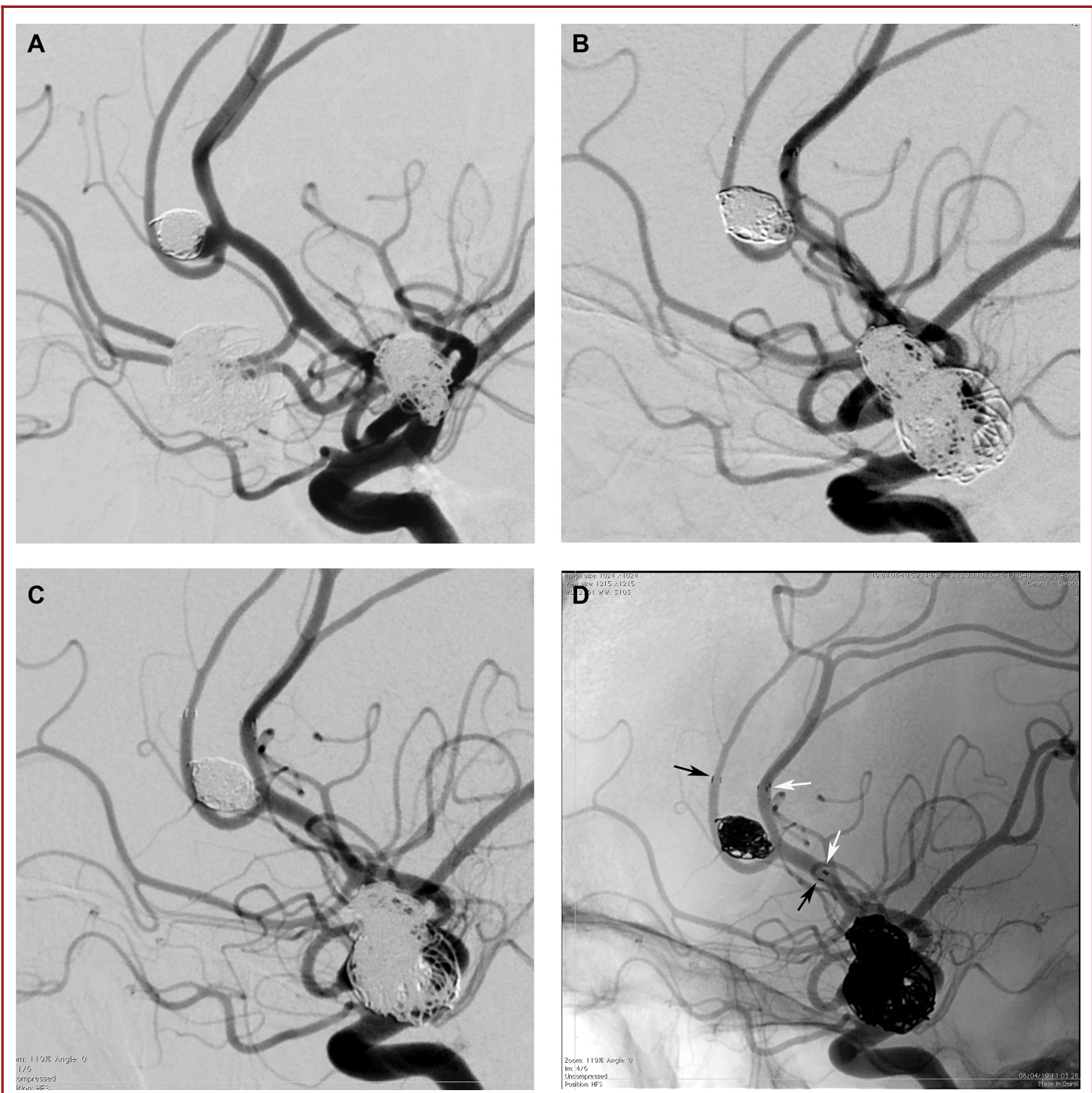

FIGURE 2. Procedural and follow-up angiography images of a 53-yr-old male patient with an unruptured, recurrent pericallosal aneurysm that had been previously treated with the balloon-assisted coiling technique. A, Preprocedural DSA images showing recurrent filling of the aneurysm sac located on the bifurcation between the pericallosal and callosomarginal branches of the anterior cerebral artery. Note that 2 other MCA aneurysms that were treated previously with the balloon and stent-assisted coiling procedures. B, Immediate postprocedural DSA image revealing the RR class 2 occlusion with a minimal filling in the neck of the aneurysm. C. Six-month follow-up DSA image demonstrating the complete occlusion of the aneurysm as a result of progressive thrombosis during the follow-up period. D, Six-month follow-up nonsubtracted angiography image shows 2 Neuroform Atlas stents deployed into the pericallosal and callosomarginal branches (black and white arrows) in Y configuration.

in these studies was very limited, and the safety and feasibility of this device for the treatment of Acom and MCA aneurysms therefore needs to be further investigated. Moreover, because neck-reconstruction devices, including the PulseRider, have no flow diversion effect that could decrease hemodynamic stress on the aneurysm neck, the long-term angiographic results obtained in aneurysms treated with neck-reconstruction devices will need to be investigated. ${ }^{21,22}$ Flow diversion is another recently described strategy for the endovascular treatment of complex bifurcation aneurysms. However, the role of flow diversion in bifurcation aneurysms is controversial, and the safety and efficacy of the flow diversion technique for the treatment of bifurcation 

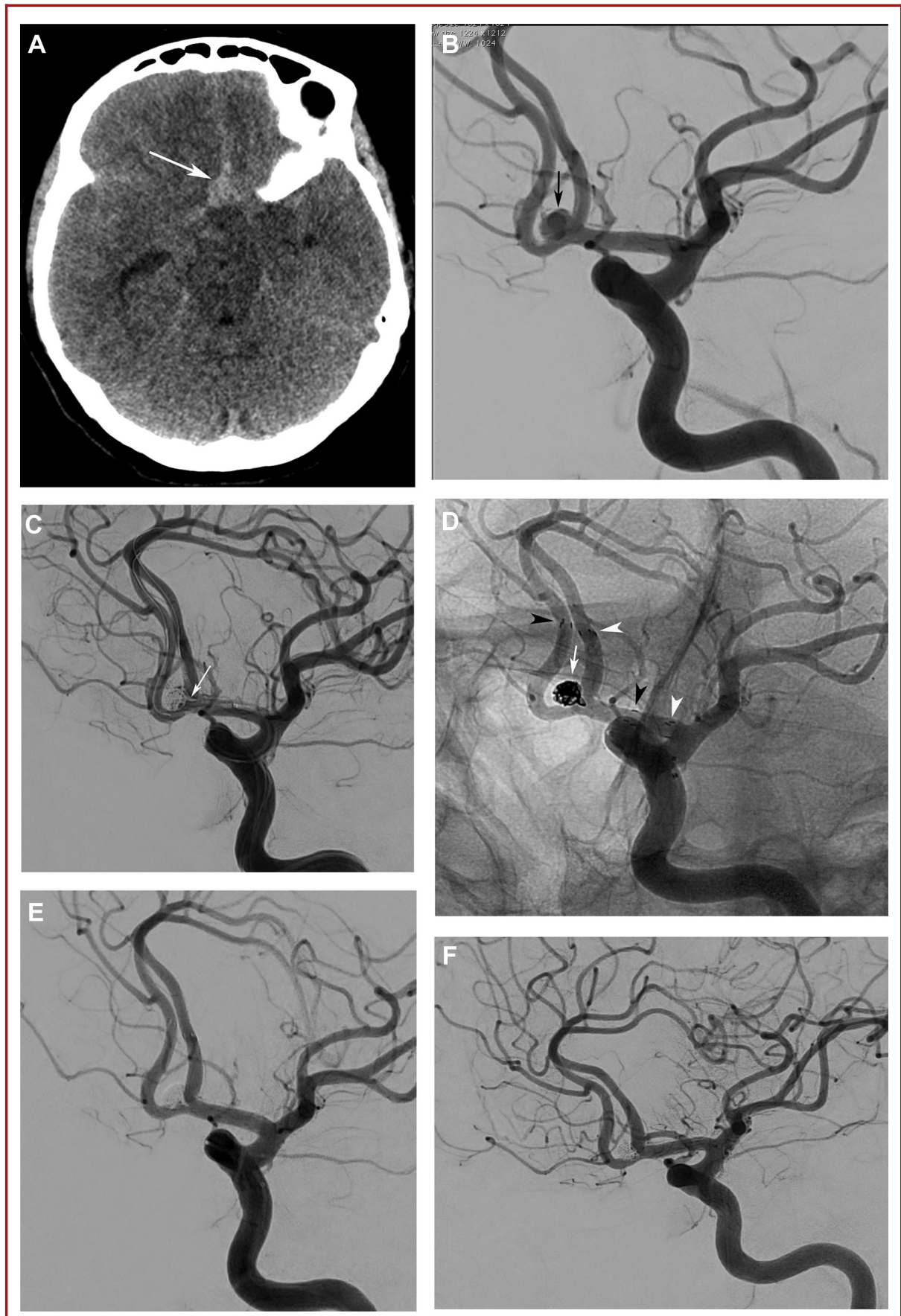

FIGURE 3. Procedural and follow-up angiography images of a 60-yr-old female patient with a ruptured Acom aneurysm. A, Preprocedural cranial computed tomography image showing subarachnoid hemorrhage (white arrow). B, Preprocedural DSA image showing a wide-necked 4-mm aneurysm (black arrow) located in the Acom. C, Procedural DSA image shows the protrusion of coil loops (white arrow) into the parent artery during the initially attempted double balloon-assisted coiling procedure. D, Immediate postprocedural control nonsubtracted angiography and image demonstrating the successful deployment of 2 Neuroform Atlas stents (arrowheads) and stable coil mesh inside the aneurysm sac (white arrow) and the complete occlusion of the aneurysm (Raymond class 1). $\mathbf{E}$, Immediate postprocedural DSA image showing the complete occlusion of the aneurysm. F, Twelve-month follow-up DSA image showing the complete occlusion of the aneurysm and the patency of the stents. 

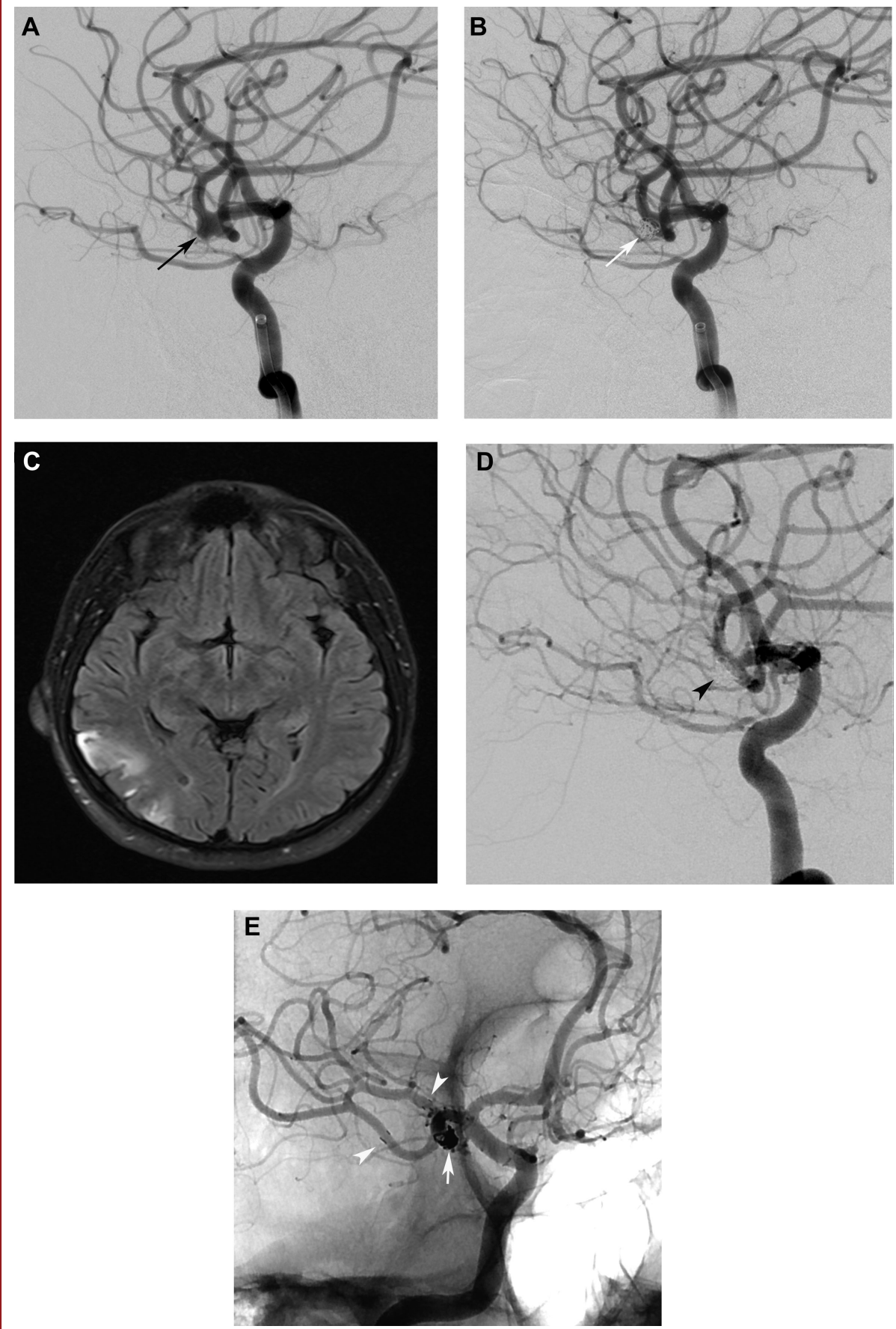

FIGURE 4. Procedural and follow-up angiography and cranial MR images of a 38-yr-old male patient with a widenecked right MCA aneurysm. A, Preprocedural DSA image showing a wide-necked MCA aneurysm (black arrow). B, Immediate postprocedural DSA image revealing the RR class 2 occlusion with a minimal filling in the neck of the aneurysm (white arrow) and patency of all vessels. C, Six-month follow-up MR image (fluid-attenuated inversionrecovery) demonstrating the subacute cortical infarction in the right temporal lobe. $\mathrm{D}$, Twelve-month follow-up DSA image showing the complete occlusion of the aneurysm (black arrowhead) and the patency of vessels. E. Twelve-month follow-up nonsubtracted angiography image demonstrating the successful deployment of 2 Neuroform Atlas stents (white arrowheads) and stable coil mesh inside the aneurysm sac (white arrow). 
TABLE 2. Immediate Post-Operative and Follow-up Aneurysm Occlusion Rates

\begin{tabular}{|lcc|}
\hline & \multicolumn{2}{c|}{ Results of Raymond class scoring } \\
\cline { 2 - 3 } Score & Immediate post-op DSA & Last follow-up DSA \\
\hline Raymond class I & $25(83.3 \%)$ & $28(93.3 \%)$ \\
Raymond class II & $4(13.3 \%)$ & $2(6.7 \%)$ \\
Raymond class III & $1(3.3 \%)$ & $0(0 \%)$ \\
\hline
\end{tabular}

aneurysms remain under question. ${ }^{23}$ Double stent-assisted coiling techniques, including Y-stenting, remain an eligible endovascular method for the treatment of complex bifurcation aneurysms.

Y-stenting requires the successful execution of several sequential endovascular maneuvers. Catheterization and navigation into sharply angulated side branches may be the most challenging part of the Y-stent-assisted coiling. In the present study, the technical success rate of the Y-stent-assisted coiling procedures was considerably high (100\%). Low-profile stents allow for easier catheterization and navigation in smallsized, delicate vessels and enable safer stenting during the treatment of complex bifurcation aneurysms. The Neuroform Atlas stent is a recently introduced low-profile stent that can be deployed through low-profile microcatheters. The use of lowprofile microcatheters for stenting might facilitate navigation into the angulated side branches and impede the development of any technical complication in our cases. Bartolini et $\mathrm{al}^{6}$ reported the results of $\mathrm{Y}$ - and X-stent-assisted coiling procedures in 97 patients. In the majority of their cases, they used various combinations of open- and closed-cell, self-expandable stents that could be delivered through microcatheters with an internal diameter of $0.021 \mathrm{in}$. They reported a complication rate of $18 \%$, and they stated that the navigation of the microcatheters in angulated side branches was the major technical problem in their cases. The catheterization of the second side branch by passing the catheter through the struts of the first stent and the adequate expansion of the second stent at the intersection point are the other complicating stages of the Y-stenting procedure. ${ }^{6}$ Attempts to perform catheterization through the stent struts may result in the dislocation of the first stent. ${ }^{6,11}$ The catheterization of the second side branch was performed by crossing the first deployed stent and was smooth and uneventful in all of our cases. However, the attempts for catheterization of aneurysm sac through the stent struts may cause the dislodgment of stent(s). ${ }^{16}$ Therefore, we preferred to jail the coiling microcatheter in the aneurysm sac before the deployment of stents to avoid the catheterization maneuvers inside the stents. Additionally, we observed no technical complications during the deployment of the second stents. The Neuroform Atlas is a laser-cut stent with a hybrid cell design that combines open and closed cells. The middle part of the stent has an open-cell design, although the proximal end has a closed-cell structure. ${ }^{24}$ The open-cell design of the Neuroform Atlas stent might have facilitated the catheterization maneuvers in our cases. The use of a relatively low-profile microcatheter for stent delivery might also have contributed to the absence of technical complications that may develop during the attempt to perform the second side-branch catheterizations. The results of this study indicate that Y-stent-assisted coiling performed using 2 Neuroform Atlas stents is a feasible endovascular method for the treatment of complex bifurcation aneurysms.

In the current study, a clinical complication developed in $6.7 \%$ of the cases, and permanent morbidity developed in $3.3 \%$ of the patients. The clinical complication rate in the current study was considerably lower than the complication and morbidity rates achieved in previous Y-stent-assisted coiling studies. Spiotta et $\mathrm{al}^{10}$ assessed the medium-term results of Y-stent-assisted coiling procedures performed using first- and second-generation Neuroform stents that could be deployed through 0.027 and 0.021 -inch microcatheters. They reported a periprocedural complication rate of $31.6 \%$. A delayed thromboembolic complication developed in $10.6 \%$ of their cases. Bartolini et $\mathrm{al}^{6}$ reported a periprocedural complication rate of $19.6 \%$ and a permanent morbidity rate of $10 \%$ following Y-or X-stent-assisted coiling. Akgul et $\mathrm{al}^{11}$ assessed the results of performing the Y-stent-assisted coiling with various combinations of Neuroform and closed-cell Enterprise stents. They reported a permanent morbidity rate of $9.1 \%$. Two metaanalyses that investigated the outcomes of aneurysms treated with the Y-stent-assisted coiling procedure found that the procedurerelated complication rate was between $8.9 \%$ and $12 \%$. ${ }^{25,26}$ The open-cell stents were preferred in the first descriptive cases of Y-stenting. The authors reasoned that the open-cell design of the first deployed stent could permit better expansion of the second stent, which was deployed at the interstices of the first stent. Although several studies reported the safety and efficacy of performing Y-stenting using closed-cell and braided stents, it remains concerning that the closed-cell design of the first stent may cause undesirable synching of the second deployed stent because of its constrained interstices. ${ }^{27,28}$ In our cases, the opencell design of the Neuroform Atlas stent may have promoted the sufficient expansion of the second stent at the intersection point. The Neuroform Atlas stent combines the advantages of lowprofile deployment microcatheters with an open-cell structure to achieve a safe and successful Y-stenting procedure.

The immediate aneurysm occlusion rate of $83.3 \%$ achieved in the current study is comparable with the results of previous Y-stenting studies. Limbucci et $\mathrm{al}^{27}$ reported an immediate occlusion rate of $87.5 \%$ in patients treated with Y-stent-assisted coiling performed using 2 closed-cell stents. A recent metaanalysis that investigated the angiographic outcomes of Y-stentassisted coiling procedures reported an immediate occlusion rate of $82.2 \% .^{25}$ In a recent study, Ciccio et $\mathrm{al}^{16}$ observed a relatively lower immediate complete aneurysms occlusion rate of $60 \%$ following double stent-assisted coiling with the Neuroform Atlas stent. However, $87.5 \%$ of partially coiled aneurysms showed progressive to thrombosis in their case series. In our series, 2 of 4 aneurysms with partial filling on the immediate postprocedural DSA showed progressive occlusion (50\%), and a complete 

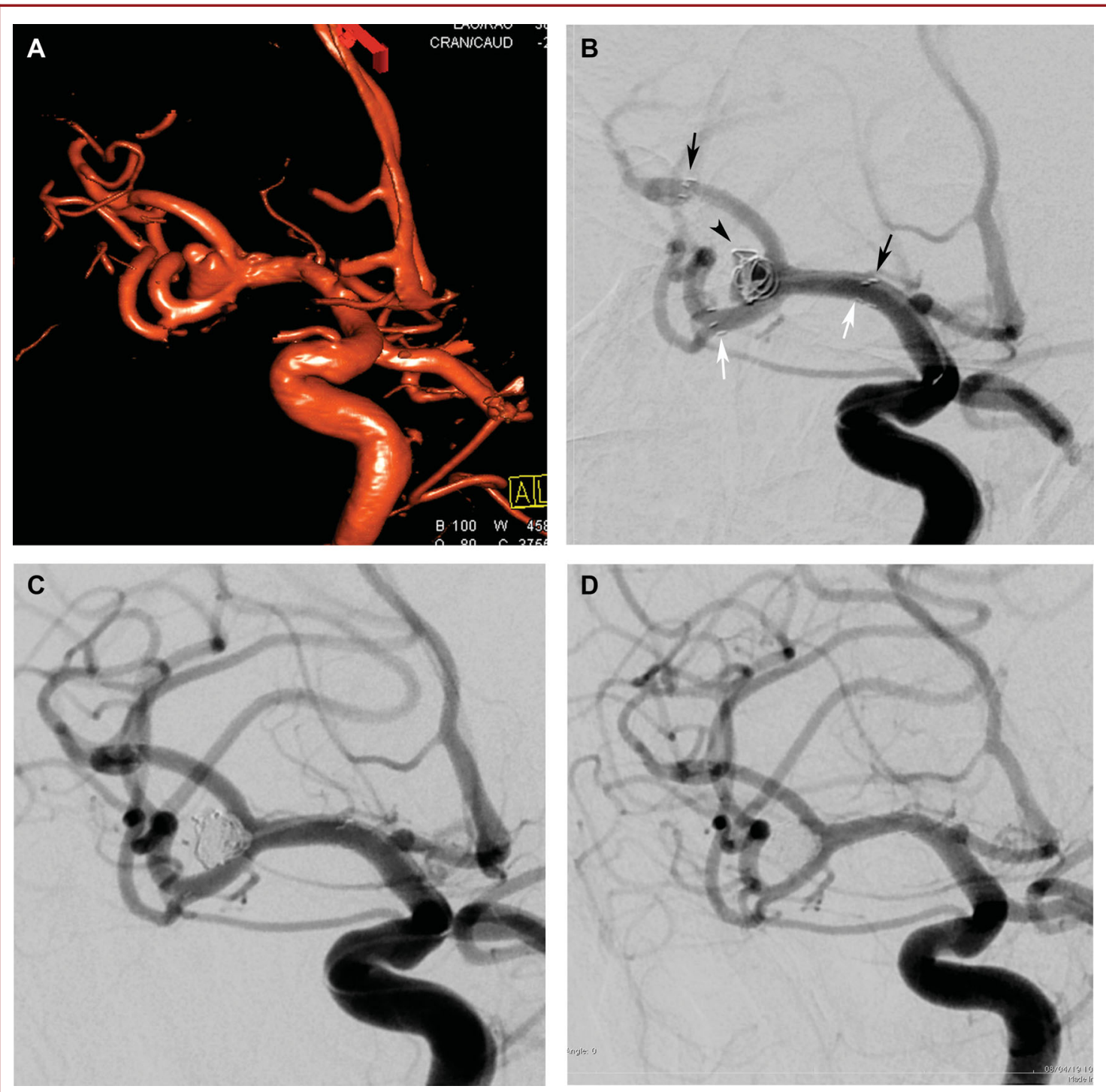

FIGURE 5. Procedural and follow-up angiography images of a 56-yr-old male patient with an unruptured MCA aneurysm. A, Preprocedural DSA image showing a wide-necked MCA aneurysm. B, Procedural DSA image showing the deployment of 2 Neuroform Atlas stents into the $M C A$ trunks (arrows) and coiling of the aneurysm sac (arrowhead). C, Immediate postprocedural DSA image revealing the complete occlusion of the sac and patency of all vessels. D, Six-month follow-up DSA image demonstrating the complete occlusion of the aneurysm.

occlusion rate of $93.3 \%$ was achieved during a mean followup period of $11.8 \mathrm{mo}$. The follow-up aneurysm occlusion rate in our study is comparable to those reported in previous studies. In a meta-analysis that investigated the outcomes of the Y-stent-assisted coiling, Cagnazzo et $\mathrm{al}^{25}$ found that the longterm complete or near complete aneurysm occlusion rate was 95.4\%. The recurrence risk is significantly lower for aneurysms treated with stent-assisted coiling than in those treated with primary coiling or balloon remodeling techniques. ${ }^{29,30}$ Stents exert biological and hemodynamic effects on the parent arteries to promote the progressive thrombosis of the aneurysms and reduce the risk of recanalization. ${ }^{29}$ The results of the current study show that performing the Y-stent-assisted coiling procedure using 2 Neuroform Atlas stents is an effective and durable treatment for wide-necked, complex bifurcation aneurysms.

\section{Limitations}

First, this study was a nonrandomized retrospective study. Therefore, there was no control group of patients who underwent alternative endovascular treatments. Additionally, the effect(s) of patient selection bias cannot be excluded from the results. 


\section{CONCLUSION}

Neuroform Atlas stent combines the advantages of low-profile deployment microcatheters with an open-cell structure to achieve a safe and successful Y-stenting procedure. The favorable angiographic and clinical outcomes of this study demonstrate that Y-stent-assisted coiling performed with Neuroform Atlas stents provides a safe, effective, and durable endovascular treatment option for wide-necked complex bifurcation aneurysms.

\section{Disclosures}

The authors have no personal, financial, or institutional interest in any of the drugs, materials, or devices described in this article.

\section{REFERENCES}

1. Akpek S, Arat A, Morsi H, et al. Self-expandable stent-assisted coiling of widenecked intracranial aneurysms: a single-center experience. AJNR Am J Neuroradiol. 2005;26(5):1223-1231.

2. Lopes DK, Johnson AK, Kellogg RG, Heiferman DM, Keigher KM. Long-term radiographic results of stent-assisted embolization of cerebral aneurysms. Neurosurgery. 2014;74(3):286-291.

3. Piotin M, Blanc R. Balloons and stents in the endovascular treatment of cerebral aneurysms: vascular anatomy remodeled. Front Neurol. 2014;5:41.

4. Chow MM, Woo HH, Masaryk TJ, Rasmussen PA. A novel endovascular treatment of a wide-necked basilar apex aneurysm by using a Y-configuration, double-stent technique. Am J Neuroradiol. 2004;25(3):509-512.

5. Menendez JY, Harrigan MR. X-configuration stent-assisted coiling. World Neurosurg. 2010;74(1):143-144.

6. Bartolini B, Blanc R, Pistocchi S, Redjem H, Piotin M. "Y" and "X" stent-assisted coiling of complex and wide-neck intracranial bifurcation aneurysms. AJNR Am J Neuroradiol. 2014;35(11):2153-2158.

7. Akmangit I, Aydin K, Sencer S, et al. Dual stenting using low-profile LEO baby stents for the endovascular management of challenging intracranial aneurysms. AJNR Am J Neuroradiol. 2015;36(2):323-329.

8. Aydin K, Sencer S, Barburoglu M, et al. Midterm results of T-stent-assisted coiling of wide-necked and complex intracranial bifurcation aneurysms using low-profile stents. J Neurosurg. 2017;127(6):1288-1296.

9. Fargen KM, Mocco J, Neal D, et al. A multicenter study of stent-assisted coiling of cerebral aneurysms with a Y configuration. Neurosurgery. 2013;73(3):466-472.

10. Spiotta AM, Gupta R, Fiorella D, et al. Mid-term results of endovascular coiling of wide-necked aneurysms using double stents in a Y configuration. Neurosurgery. 2011;69(2):421-429.

11. Akgul E, Aksungur E, Balli T, et al. Y-stent-assisted coil embolization of wideneck intracranial aneurysms. A single center experience. Interv Neuroradiol. 2011;17(1):36-48.

12. Aydin K, Arat A, Sencer S, Barburoglu M, Men S. Stent-assisted coiling of wideneck intracranial aneurysms using low-profile LEO baby stents: initial and midterm results. AJNR Am J Neuroradiol. 2015;36(10):1934-1941.

13. Cay F, Peker A, Arat A. Stent-assisted coiling of cerebral aneurysms with the Neuroform Atlas stent. Interv Neuroradiol. 2018;24(3):263-269.

14. Ten Brinck MFM, de Vries J, Bartels RHMA, Grotenhuis JA, Boogaarts HD. Neuroform Atlas stent-assisted coiling: preliminary results. Neurosurgery. 2019;84(1):179-189.

15. Jankowitz B, Hanel R, Jadhav A, et al. Neuroform atlas stent system for the treatment of intracranial aneurysm: primary results of the atlas humanitarian device exemption cohort. J NeuroIntervent Surg. 2019;11(8):801-806.

16. Ciccio G, Robert T, Smajda $S$, et al. Double stent assisted coiling of intracranial bifurcation aneurysms in $\mathrm{Y}$ and $\mathrm{X}$ configurations with the Neuroform Atlas stent: immediate and mid term angiographic and clinical follow-up. J NeuroIntervent Surg. published online: 2019 (doi: 10.1136/neurintsurg-2019-015175).
17. Caragliano AA, Papa R, Pitrone A, et al. The low-profile Neuroform Atlas stent in the treatment of wide-necked intracranial aneurysms-immediate and midterm results: an Italian multicenter registry. J Neuroradiol. published online: 2019 (doi: 10.1016/j.neurad.2019.03.005).

18. Raymond J, Roy D. Safety and efficacy of endovascular treatment of acutely ruptured aneurysms. Neurosurgery. 1997;41(6):1235-1246; discussion 45-46.

19. Popielski J, Berlis A, Weber W, Fischer S. Two-center experience in the endovascular treatment of ruptured and unruptured intracranial aneurysms using the WEB device: a retrospective analysis. AJNR Am J Neuroradiol. 2018;39(1):111-117.

20. Kabbasch C, Goertz L, Siebert E, et al. Factors that determine aneurysm occlusion after embolization with the Woven EndoBridge (WEB). J NeuroIntervent Surg. 2019;11(5):503-510

21. Gory B, Spiotta AM, Mangiafico S, et al. Pulse rider stent-assisted coiling of wideneck bifurcation aneurysms: periprocedural results in an international series. AJNR Am J Neuroradiol. 2016;37(1):130-135.

22. Spiotta AM, Derdeyn CP, Tateshima S, et al. Results of the ANSWER trial using the pulse rider for the treatment of broad-necked, bifurcation aneurysms. Neurosurgery. 2017;81(1):56-65.

23. Topcuoglu OM, Akgul E, Daglioglu E, et al. Flow diversion in middle cerebral artery aneurysms: is it really an all-purpose treatment? World Neurosurg. 2016;87:317-327.

24. Ulfert C, Pham M, Sonnberger M, et al. The Neuroform Atlas stent to assist coil embolization of intracranial aneurysms: a multicentre experience. J NeuroIntervent Surg. 2018;10(12):1192-1196.

25. Cagnazzo F, Limbucci N, Nappini S, et al. Y-stent-assisted coiling of wideneck bifurcation intracranial aneurysms: a meta-analysis. AJNR Am J Neuroradiol. 2019;40(1):122-128.

26. Granja MF, Cortez GM, Aguilar-Salinas P, et al. Stent-assisted coiling of cerebral aneurysms using the Y-stenting technique: a systematic review and meta-analysis. J NeuroIntervent Surg. 2019;11(7):683-689.

27. Limbucci N, Renieri L, Nappinin S, Consoli A, Rosi A, Mangiafico S. Y-stent assisted coiling of bifurcation aneurysms with Enterprise stent: long-term followup. J NeuroIntervent Surg. 2016;8(2):158-162.

28. Spiotta AM, Lena J, Chaudry MI, Turner RD, Turk AS. Y-stenting for bifurcation aneurysm coil embolization: what is the risk? Stroke Res Treat. 2014;2014:762389.

29. Chalouhi N, Starke RM, Koltz MT, et al. Stent-assisted coiling versus balloon remodeling of wide-neck aneurysms: comparison of angiographic outcomes. AJNR Am J Neuroradiol. 2013;34(10):1987-1992.

30. Raymond J, Darsaut TE, Bing F, et al. Stent-assisted coiling of bifurcation aneurysms may improve endovascular treatment: a critical evaluation in an experimental model. AJNR Am J Neuroradiol. 2013;34(3):570-576.

\section{COMMENT}

7 he authors present a series of 30 patients treated with the Atlas stent in a "Y" configuration. The authors are to be commended for their very low complication rate (permanent morbidity of 3.3\%) and high aneurysm occlusion rate (93\% at a mean of 11 months). The Atlas and other similar stents represent a significant improvement in the treatment of aneurysms due to their ability to be deployed through a standard 017 catheter as opposed to a larger catheter, which allows for the catheterization and treatment of small, tortuous branch vessels. The authors illustrate this point nicely with their cases and by measuring the diameter of branch vessels catheterized.

The major limitations of this paper are the retrospective, single center, self-reported outcomes. This paper represents the third recently published series on Atlas "Y" stenting, which adds to the knowledge of the nuances of this important treatment.

Jonathan Andrew Grossberg Atlanta, Georgia 